\title{
From Divergence to Convergence: Towards Integration of Cognitive Linguistics and Critical Discourse Analysis in Political Discourse
}

\author{
Qian Wang \\ Northwestern Polytechnical University, \\ Xi'an, Shaanxi, China
}

\begin{abstract}
The social turn of cognitive linguistics and cognitive turn of critical discourse analysis breed the opportunity for cognitive linguistics and critical discourse analysis to develop towards a more converging path that integrates both cognitive and social dimensions of language. As known, political discourse is intrinsically persuasive and always informs a power relation with attempts to achieve effectiveness of persuasion. This paper argues that both approaches (Cognitive Linguistics and CDA) are concerned with surfaced evidence of implicit ideologies hidden behind political discourse, so the integration of CL and CDA could extend the research scope for both paradigms on one hand, and provide more powerful explanatory tools to augment our understanding of the intertwined relations between language, cognition and society on the other.
\end{abstract}

Key words: cognitive linguistics; critical discourse analysis; political discourse; integration

\section{INTRODUCTION}

Both Cognitive Linguistics (henceforth CL) and Critical Discourse Analysis (henceforth CDA) have developed into quite influential research paradigms since 1970s. CL centers on studies that uncover how language functions as a cognitive ability through conceptual metaphor, constructing mental space and online conceptual blending whereas CDA analysts primarily revolve around how language represents ideological discursive practice through texts produced in social context. The rationale of political discourse is, in essence, rooted in the consent of its audience, all the more so within a political system that defines and frames itself as democratic. Therefore, it is hard to conceive of a type of political discourse which is free from any form of ideological imposition. Given that political discourse, being potentially manipulative, is intrinsically persuasive and always informs a power relation with attempts to achieve effectiveness of persuasion. In this sense, a cognitive approach which interrogates the pragmatic aspect of the persuasive process through which a given ideological paradigm is configured and transmitted has a role to play. Hence, though CL and CDA are somewhat divergent in their analytical approaches to language, both of them, as a matter of fact, intend to uncover what hides behind the linguistic expressions and therefore, gradually develop towards a more converging path that integrates both cognitive and social dimensions of language.

\section{THE SOCIAL TURN OF COGNITIVE LINGUISTICS}

Emanated from a branch of linguistics, CL describes interactions of language and cognition through psychological lens. Developmental trajectories for Cognitive Linguistics could be briefly summarized as follows: (1) The pioneering stage (1975-1987). This period witnessed a substantial number of research undertaken by some leading figures like Talmy's work (1975) on figure and ground, Langacker' s work (1976) on cognitive grammar; at that time, Lakoff (1977) was moving towards what he termed as Gestalt linguistics. (2)The expansion stage (1987-1996). During this period, Langacker published his work Foundations of Cognitive 
Grammar in 1987, George Lakoff's monograph Women, Fire and Dangerous Things came out in the same year, together with an important collective volume of papers edited by Brygida Rudzka-Ostyn emerging in 1988. In 1989, the first International Cognitive Linguistics Conference was held and the journal Cognitive Linguistics was lunched. (3) The consolidation stage (1996-2007). This decade was characterized by a growing body of publications in Cognitive Linguistics, as contributed by Ungerer \& Schmid (1996), Dirven \& Verspoor (1998), Croft \& Cruse (2004), to just name a few.

CL subscribes to experience philosophy with emphasis on the mental experience, cognitive unconsciousness and the metaphorical thoughts. In addition, CL attaches importance to conceptual structure and the study of meaning, endeavoring to seek the cognitive mechanism underlying the language facts and make a unified interpretation of language through cognitive methods and cognitive structures. While revealing the cognitive role Language plays in shaping the our mode of thinking, some CL scholars have recognized the necessity of going beyond the individual mind for expanding explanatory dimensions. For example, Lakoff's interest in analyzing cultural and political issues (Lakoff, 1987, 2006, 2008) has paved way for delving into how American politics is understood with the help of metaphorical mappings and cognitive models. In his analyses, he has been aware of the relationship between the mental processes and the social sphere. Gibbs, a psychologist working within CL, also stresses "metaphor and its relation to thought as cognitive webs that extend beyond individual minds and are spread out into the cultural world" (Gibbs, 1999, p.146). Likewise, Hawkins (1997) suggests that on top of the individual mind, meaning in the social sphere should be investigated, which actually is in line with Langacker's (1988) perspective to view CL as usagebased linguistics. Apart from these linguists mentioned above, other researchers' publications in recent decade have been making plea for a social turn in CL, calling for incorporating socialcognitive perspective on the nature of language (Harder, 2010; Kristiansen \& Dirven, 2008; Croft; 2009; Geeraerts, 2016).

In fact, actual usage of language could assist in collecting linguistic experience with which interactants may use language to do numerous things more than just relying on linguistic constructions in social encounters, as instantiated in resorting to both linguistic and nonlinguistic acts (Austin, 1962). Certainly, as assumed that one of the metafunctions of language is interpersonal function (Halliday, 1985), social variables such as social environment, social status, or social relations should not be excluded and neglected. It is apparent that CL has been subject to criticism for neglecting interactions among language, cognition, and contextual factors. Against this backdrop has emerged a new discipline - Cognitive Sociolinguistics which intends to extend the cognitive paradigm into the regional and social patterns involved in linguistic symbolization. In addition, Cognitive Sociolinguistics also attempts to look into the differentiated conceptual links between language and culture, as laid down in the concept of cognitive cultural models (Kristiansen \& Dirven, 2008). The sociocognitive approach, without fail, brings new insights into relations between language, cognition and communication since, for example, use of metaphor emanates both from embodied mind and interpretations of ongoing communicative situation.

\section{THE COGNITIVE TURN OF CRITICAL DISCOURSE ANALYSIS}

Originated from Critical Linguistics around 1979, CDA is deemed as a type of discourseanalytical research which investigates the way in which ideology, identity and inequality are enacted through texts produced in social and political contexts (van Dijk, 2008). CDA researchers are convinced that though use of language is viewed as a social tool, in essence, it becomes a form of ideology to intervene the expressions of reality. Hallidayan Systemic Functional Linguistics (SFL) which argues for using language as a means of social interaction 
exerts a strong influence on CDA. Since language is "a resource for reflecting on the world" (Halliday \& Matthiessen, 1999, p.7), SFL could provide the toolkit for deconstructing the socially-constructed machinery of power and revealing the underlying ideologies in discourse (Fairclough, 2001; Wodak, 2001; Chilton, 2005a), particularly if nominalisations and agentless passive constructions are examined (e.g., Fowler, 1991; Fairclough, 1989). With reference to political discourse, CDA scholars share the perspective that human social interaction (especially via linguistic discourse) is a site of political struggle for resources. In addition, another common view reflects a heightened sensitivity to the ways political elites exploit language to construct and to reproduce asymmetrical and oppressive social hierarchies of power. Furthermore, CDA scholars aspire to make explicit in their analyses hidden political moves on the part of the political elite so that conventionalized hierarchies may be challenged and eventually dismantled. A final shared notion is the acknowledgement of the potential influential power of language to shape our society.

When some scholars realize that CDA studies on the basis of SFL only touch upon the process of discourse production and fail to take reader's active role into account when interpreting and comprehending the discourse, they begin to lay emphasis on the mediating role of cognitive model and human mind in discourse and context, language use and social construction. For instance, van Dijk proposes the social-cognitive approach to the critical analysis of the political discourse and the approach presents one model which connects textual, cognitive and social structures. For van Dijk (1985, 2008, 2009), textual structure and social structure are mediated by social cognition, which is defined as "the system of mental representations and processes of group members" (van Dijk, 1995, p. 18). Although it is embodied in the minds of individuals, social cognition is social "because it is shared and presupposed by group members" (van Dijk, 1993, p. 257), and it can be referred in a more abstract sense as ideologies, attitudes, prejudices, opinions, etc. Since van Dijk acknowledges that the importance of macro-level notions such as social relations and micro-level notions such as discourse are mediated by social cognition, his approach thus is named the discoursecognitive-society triangle as shown in the following figure.

Figure 1 Discourse-cognitive-society triangle (Van Dijk, 1998, P.125)

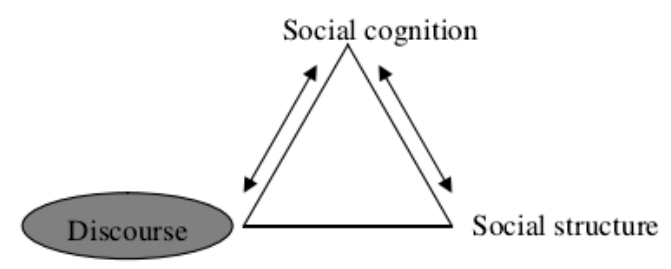

As shown in this figure, the dialectical nature of the relationship between discourse and social structure is denoted by the two bidirectional arrows with the shaded area becoming the micro focus of CDA. Van Dijk believes that a group who has power can not only restrict the action of the inferior group but also have an impact on their thinking. As a matter of fact, in modern society, the power group controls the powerless by virtue of resorting to strategies such as persuasion, disguise, cognitive manipulation and so on, to meet the interest of a certain group. Hence, when CDA attempts to explain the power-related discourse structures, the social and cognitive processes in the production of these structures have to be revealed. Same as the other CDA scholars, Wodak believes that the relationship between discourse and social practice is dialectical. On the one hand, social reality rules and restricts the discursive trajectory; on the other hand, discursive strategies, in turn, maintain, shape or influence the social reality. What Wodak wants to explore is the intermediary role of human's cognition and knowledge between discourse and society. Wodak (2006) points out that almost all of the 
people believe that there are some mental processes which can link the generation and interpretation of discourse both with the social phenomenon and the dominant discourse. In the analysis of the attitude through people's language as well as the prejudice and stereotypes they held toward a specific group, such association will be very obvious. In fact, Wodak (2001) integrates many notions of cognitive science, such as "frames", "schema", "scripts" into her own discourse-historical approach, and further stresses that CDA must fully consider the social psychology, cognition and language in the generation of discourse. Our knowledge of social and political realities is not derived from our direct perception or personal experience but rather on the basis of the discourse we are exposed to. In this sense, the view that language-use construes experience and alternates grammatical structures, is shared among CL, SFL and CDA.

\section{INTEGRATION OF CL AND CDA}

As Cognitive linguists' concern about cultural variation and social interaction is increasing, and CDA underscores the intermediary role that cognition plays between discourse and society, there has been a start of the integration between CDA and CL. As articulated, on one hand, "Nobody can actually look into somebody's or one's own brain" (Wodak, 2006, p.180), suggesting that the discursive construction inherently involving cognitive processes needs to be unmasked. On the other hand, communication and human thinking share the same conceptual system, as argued that language is an important source of evidence for what the system is like (Lakoff \& Johnson, 1980) and language serves "a window to the mind" (Fauconnier, 1997, p.96). As a result, cognitive approach with which to address a dialectic between a textual and macrostructural analysis, could assist in disclosing how the conceptual processes function in the communication of ideology, and thus shed new light on the critical assessment of these ideologies.

In CL, language representation and ideology (or cognitive model) can be connected through metaphor, which lies at the heart of explaining how discourse can be used to mirror our society. As claimed, CL, through examining pervasiveness and persuasiveness of metaphor, can "contribute to a situation where they privilege one understanding of reality over others" (Chilton, 1996, p.74), whereby what bridges the text production and text comprehension could be identified. Conceptual Metaphor Theory (CMT) (Lakoff \& Johnson, 1999) and Conceptual Blending Theory (CBT) (Fauconnier \&Turner, 2002), as two approaches probing into metaphor could be possibly available for appropriation in CDA. Charteris-Black put forward that metaphor is "central to critical discourse analysis since it is concerned with forming a coherent view of reality" (Charteris-Black, 2004, p.28) and in the meantime, frames unequal power relations existing in society (Fairclough, 2001). This idea has been corroborated by some studies in demonstrating the pervasiveness of metaphor in constructing our social, cultural as well as ideological thinking through conceptual processes, which resonates with the manipulation and control embedded in language in CDA (Perrez \& Reuchamps, 2015). These conceptual processes are regarded as "construal operations" by cognitive linguists. Langacker (1991) defines construal as that the same event or situation which is potentially conceptualized in many different ways, but only one of the alternative structures can be used to encode some particular conceptualization. He further expresses the essence of construal as "in viewing a scene, what we actually see depends on how closely we examine it, what we choose to look at it, which element we pay most attention to, and where we view it from" (Langacker, 2008, p.55). In discourse, linguistic structures reflect the text-producers' own ideologies, manifested through conceptualization of events the text-producers, intend to create in order to realize certain goals. The concept of contrual in $\mathrm{CL}$, therefore, shares common grounds with the relativism of CDA which contends that text representation is "always representation from some ideological point of view, as managed through the inevitable structuring force of transitivity' (Fowler, 1991, p. 85). Hart (2011) highlights some of the most 
significant construal operations for CDA, such as profiling/back-grounding, categorization, metaphor, metonymy, epistemic modality and so on. As argued by CL, metaphor shapes our way of thinking and reasoning, playing a very important role for us to structure and perceive the world. This means metaphors in discourse is not only a strategy for the text-producers to impose a certain ideology to the text-consumers, but also represents the way how the world is conceptualized by text-producers.

In a word, CL researchers from the cognitive semantic tradition have given increasing attention to meaning derived from situational context and in the meantime, as was discussed above, CDA studies acknowledge the important role mental process plays in understanding the world and mediating between discourse and society, thereby breeding opportunities for the possible integration. CL, at the micro-level, equip CDA researchers with powerful apparatus with which metaphor could be interpreted in political discourse. Conceptual Metaphor Theory (CMT) and Conceptual Blending theory (CBT) are two accounts of metaphor in CL. The two theories both view metaphor as a conceptual phenomenon rather than a purely linguistic one, involving systematic projection between conceptual domains. Furthermore, both defend that apart from language, imagery and inferential structure can also be projected. It should be noted, however, they do have distinctions in a way that CMT focuses on the relationships "between pairs of mental representations", while CBT involves more than two; "in CMT, metaphor is a strictly directional phenomenon, while BT is not" (Grady et al. 1990, p.101).

\section{CMT and CDA}

Reinvigorating the debate on origin and function of metaphors, Lakoff and Johnson's publication Metaphors We Live By redefines metaphor as a cognitive tool in human coherent conceptual system by means of which abstract knowledge of social realities is structured (Lakoff and Johnson, 1980; Charteris-Black, 2005; Walter \& Helmig, 2008). CMT claims metaphors can map structure from a source domain to a target domain but not vice versa and thus mapping is unidirectional. This may explain why there should be a pattern to predict which domain typically function as source domain and which function as target one. Chilton (2005b) states, "source domains have a clear tendency to be based in human physiological experience", so they are more concrete and therefore more readily "graspable", while "the target domains are more abstract, understructured or problematic conceptual areas. (Chilton, 2005b, p. 7)"

The cross-domain mappings, in line with what CDA analysts contend, are by no means automatic and unconscious but rather strategic in communicative purposes, as Charteris-Black claims that the choices of metaphor in discourse embodies the ideology of text-producers since metaphors could "provide particular insight into why the rhetoric of political leaders is successful" (Charteris-Black, 2004, p. 197). In political discourse, social and ideological dimensions could be generated, manifested and sustained by virtue of metaphorical expressions which entail hidden intentions of text producers. In this sense, Critical Metaphor Analysis (CMA) provides a lens through which ideological configurations together with hidden power relations in the realm of political discourse could be unmasked. To date, there have been numerous attempts in utilizing CMA in identifying, interpreting and explaining metaphors across a range of discourse in shaping public attitudes. (see, for example, Chilton, 1996; Beer \& De Landtsheer, 2004; Santa Ana, 2002; Lakoff, 1996). An example taken from the speech delivered by former President George.W. Bush is illustrated here.

E.g. (1) I will not forget this wound to our country or those who inflicted it. I will not yield, I will not rest, I will not relent in waging this struggle for freedom and security for the American people. 
A few days after 9/11, the President addressing the nation refers to the incident as a "wound" being inflicted on America. The expression "wound" can be isolated as a "metaphorical focus" (Steen, 1997) in the first sentence. The general metaphor at work here is "STATE AS PERSON" (Lakoff, 1999), allowing Bush to talk about the country as a whole in terms of a person, which as such can be subject to action/s and react to those action/s with feelings. But at a lower level of categorization in the "state as person system", there is another metaphorical process being evoked which responds to physicalization of states, events, feelings and emotions. In other words, a body politic metaphor is also operating, which can be referred to here as "bereavement is physical pain". Personification and physicalization as two basic metaphorical processes preside together over the persuasive power of the metaphorical expression. More particularly, personification of the subject of the $9 / 11$ attacks not only conveys the pathos of the victims, but also correspondingly puts emphasis on the agent of this "wound" (physicalization), and elicits a search for an enemy to be identified (as agent). A process of physicalization is also involved in the metaphorical expression identifiable in "struggle": conflict is a physical conflict- a struggle, or a fight (struggle metaphor). Declaring that he would be relentless in "waging this struggle for freedom and security for the American people", the President enunciates the "conflict frame" as a state of fact. What makes this ideological position particularly effective is its rhetorical realization in terms of a physical struggle. The concept of struggle reminds one of an action in which two sides are involved, energy is consumed and a high level of emotive participation- rage - is involved. The physicalization of the conflict in terms of a struggle, makes it more effective as an image as well as an ideological model that can be transmitted

Despite the explanatory power of critical metaphor analysis in political discourse, some CDA analysts have challenged the appropriation of CMT in CDA. For example, Hart (2008) argues that CMT is primarily concerned with the conceptual structures from which language is held to arise naturally, denoting that CMT mainly presents as evidence for conventionalized conceptual metaphors that are often not attested, but just intuitive to native speakers. Consequently, CMT is believed to be more appropriate for the interpretation of metaphorical structures uttered by individual discourse instead of political discourse which are elaborately designed not for being uttered intuitively. In addition, CMT fails to capture cognitive operations involved in interpreting metaphors though it discloses and highlights the nature of metaphor. In other words, the online processing of texts by text-consumers via cross-domain mapping cannot be captured. Moreover, according to Lakoff and Johnson, primary metaphors "are part of the cognitive unconscious," (Lakoff \&Johnson, 1999, p. 56), thus leaving no room for speakers' intentions. For CDA, however, within particular contexts, metaphors are not, to a large extent, predetermined by motor-sensory or bodily experience but chosen deliberately by speakers to fulfill a particular communicative goal (Charteris-Black, 2004). Furthermore, Linguistic metaphorical expressions refer to the "surface realization" of the underlying conceptual metaphor" (Lakoff \&Johnson, 1999, p. 203), denoting that cross-domain mappings merely occur at the conceptual level. This is in contrast with CDA which contends to some extent, linguistic representations in discourse can determine conceptual representation.

\section{CBT and CDA}

Conceptual Blending Theory derives from two theories within cognitive semantics: Conceptual Metaphor theory and Mental Space Theory. It is most closely related to Mental Space Theory considering its central focus on dynamic meaning construction instead of offline meaning construction held by CMT. Conceptual blending is a general cognitive operation on a par with analogy, recursion, mental modeling, conceptual categorization, and framing. It serves a variety of cognitive purposes. It is dynamic, supple, and active in the moment of thinking. According to Fauconnier \&Turner (2002), the essence of the operation is to construct a partial match 
between input mental spaces and to project selectively from those inputs into a novel "blended" mental space, which then dynamically develops emergent structure. The network model as illustrated in the figure 2 is concerned with on-line, dynamical cognitive work people do to construct meaning for purposes of thought and action. It focuses specially on conceptual projection as an instrument of on-line work.

Figure 2 A Four-space Conceptual Blending Network (Fauconnier \& Turner, 2002:143)

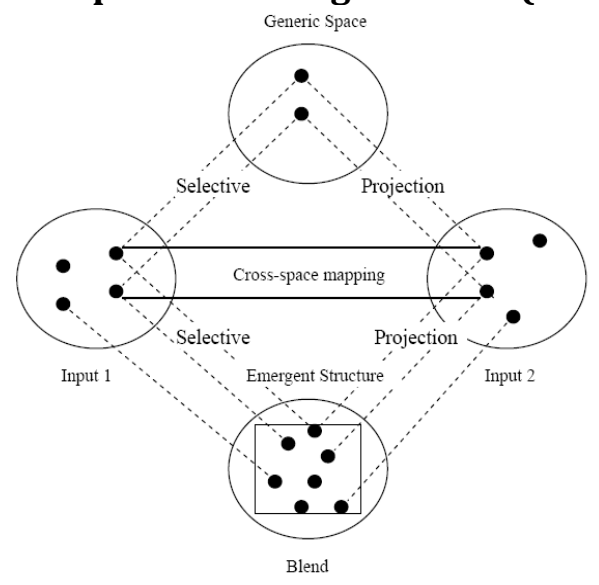

In this model, 4 mental spaces ( 2 input spaces, generic space and blend space) which contain a partial representation of the entities and relations of a particular scenario as perceived, imagined, or remembered by a interlocutor. This representation typically includes elements to represent each of the discourse entities, and simple frames to represent the relationships that exist between them. In short, a mental space is a short-term construct informed by the more general and more stable knowledge structures associated with a particular domain. Mappings between domains are at the heart of the unique human cognitive faculty of producing, transferring, and processing meaning. The generic space reflects some common, usually more abstract structure and organization shared by the inputs and defines the core cross-space mapping between them. There is a relationship of similarity between the generic space and the input space because the generic space has an image-schematic structure that is skeletal and abstract. That is to say, a generic space does not have to be available prior to the construction of a network. In stead, it is constructed and elaborated along with the other spaces and connections. Blending refers to a general cognitive operation, whereby one of the main effects of blending is the integration of several conceptual structures into a single conceptual unit. The blended space develops inferences, arguments, ideas and emotions, which can modify the initial input spaces and change our views of the knowledge used to build those input spaces. A blended space that is a rich space integrating the generic structure, structures from each input space and background information. Often the blended space has an emergent structure of its own. Blending operates on these mental spaces as inputs. These input spaces project on to separate blended spaces, which inherit partial structure from each of the possibly multiple input spaces, but also yield new emergent meaning structures. In blending, structural connections or concepts from two input mental spaces are projected to a the blend space. The projection from the inputs to the blend is selective which could be used to explain "why on different occasions, different language users, or even the same language users can produce different blends from the same inputs" (Evans, 2006, p.494). For example, metaphors of "flood of asylum seekers", "flow of immigration" give rise to the inferential structure derived from the conceptual frame of water. However, the water metaphors here are often used as topic of danger which is projected into the blended space. Like too much water in a container can be overflow and it may cause disaster. It should be noticed that structure available for recruitment from the general water frame, such as its importance in sustaining life does not get 
projected into the blend. In addition to inheriting partial structure from each input space, the blend develop "emergent" content of its own, resulting from the juxtaposition of elements from the input spaces by virtue of compositions, completion and elaboration. This blending networks are constructed according to speakers' communicative intentions. Ideologically speaking, speakers choose to recruit particular structure in order to create a certain reality. That's why compared with CMT, CBT is more compatible with CDA.

CDA adopts a social-constructivist perspective while CBT is cognitive-individualism. Conceptual blending is an online process as discourse unfolds, which is different from the conceptual frames stored in our long-term memory and entrenched in our repertoire of knowledge. However, mental spaces built up dynamically can become entrenched when shared by a group of people. According to van Dijk (2002), social cognition is shared and presupposed by group members who reside in social memory and entrenched blends have their socially shared nature and can also comprise part of the social memory. Thus to a certain extent, social cognition is equal to entrenched blends.

As Fauconnier \&Turner (2002) states, blends can become entrenched and give rise to conceptual and formal structure throughout the community. Since both social cognition and entrenched blends are mental representations and processes of group members, entrenched blends may be characterized as social cognition in one particular form. In figure 3, Hart (2008) demonstrates discourse and social structure are bidirectionally connected by social cognition. Accordingly, a corresponding model for metaphor in CDA may be diagrammatically represented as follows.

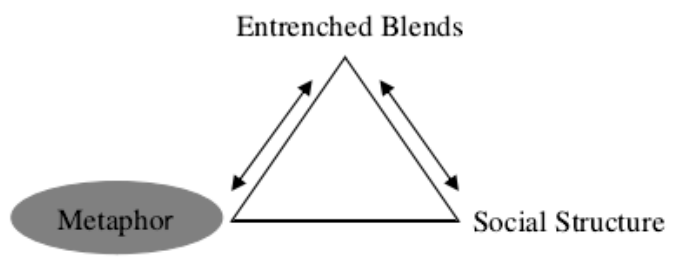

Figure 3 Metaphor in the discourse-cognition-society triangle (Hart, 2008, p.98)

As shown in the above figure, mediated by entrenched conceptual blends, metaphor in discourse can be constitutive of social structure. As Grady et al. (1991) articulates the online conceptual achievement created by individuals would become a shared, entrenched conceptualization probably for they could achieve some purpose. For example, in the political discourse, what the text-producer has composed will have certain influence on the textconsumers. When the text-consumers absorb what they have been exposed to, then the individual concept created by the text-producer will become a shared one for the textconsumers. In the meanwhile, certain intention of the text-producer will also be achieved. One primary purpose served in the construction of blends is the promotion of particular representations of reality. When blends get entrenched "they become our new construal of reality" (Fauconnier, 1997, p.168). CDA works as an approach to unveil how things come to be taken for granted and "many of our beliefs and representations might seem simply natural but are in fact naturalized (Stubbs, 1997, p.105). "The blend is frequently used to reduce textconsumers' awareness of the semantic tension and thus concealing an underlying persuasive function that is not immediately transparent" (Charteris-Black, 2004, p.21). Thus in this sense, CBT is more compatible with CDA to achieve the speakers' strategies. The metaphor "Britain as container" taken from Brexit reports from the website of the newspaper Sun (May 20, 2016) is used as an illustration for how CBT works. 
E.g.(2) Penny Mordaunt said thousands could flood in when Turkey, Albania, Macedonia, Montenegro and Serbia join. All five have far higher levels of murder, kidnap and gun ownership than Britain.

(3) The Brexit-backing minister said that between 172,000 and 428,000 migrants a year would be arriving in the UK until 2030.

(4) A staggering 80 per cent of the employment rise in the past year is accounted for by workers from outside the UK.

According to these examples, the blending network of "Britain is a container" is represented as follows (Figure 4):

Figure 4 Blending network of "Britain is a container" Metaphor

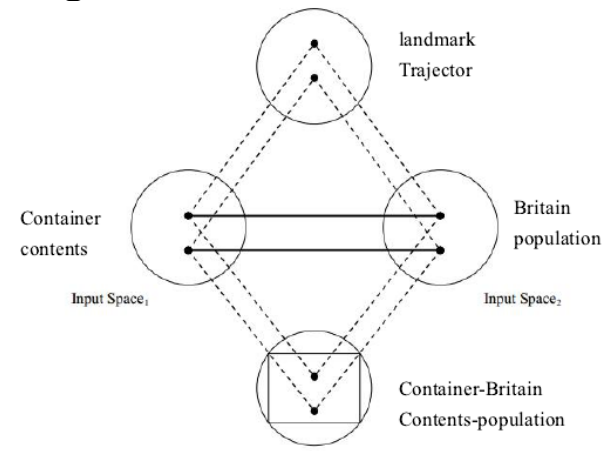

The prepositions "in" and "outside" activates the "container" schema, which is dynamic cognitive constructs which 'represent schematic patterns arising from imagistic domains' (Croft \& Cruse, 2004, p. 44). A container schema has an inherent 'logic' or topology consisting of three salient structures: an interior and exterior defined by a boundary, indicating that British people "dwell in" this container whereas immigrants are conceptualized as the external entities of the container. The corresponding elements of the two input spaces serve to activate text-consumers' background knowledge of a container while the completion of the blending process can induce the inferences that Britain has certain limit just like a container so an uncontrolled number of immigrants will exceed its capacity. This projection of the two frames stresses that the outsiders keep coming into the container to occupy the interior space and rob the interior resources. British people will naturally infer that immigrants are intruders that will, for example, steal their jobs or compete with them in public services and thus exert detrimental effect on their life. Consequently, the prejudice that British people have for immigrants will be reinforced and consolidated, thus supporting "British leaving the EU" which may be conducive to evading from the bad influence brought about by immigrants. It could be seen that the container metaphor can help to distinguish social groups by indicting people as the insiders and the outsiders.

\section{CONCLUSIONS}

Grounded in the second generation of cognitive science and experiential philosophy, Cognitive Linguistics treats people's daily experience as basis of language use, focusing on interpreting relationship between language and general cognitive ability. As a research paradigm, it could add new insights in interpreting mental construal in discourse production and comprehension by introducing cognition as a mediator between discourse and society. Given that both approaches (Cognitive Linguistics and CDA) are concerned with surfaced evidence of implicit conceptualizations, the integration of CL and CDA could extend the research scope for both paradigms on one hand, and provide more powerful explanatory tools to augment our 
understanding of the intertwined relations between language, cognition and society on the other.

\section{ACKNOWLEDGMENTS}

This study is supported by the Fundamental Research Funds for the Central Universities (G2019KY05202);Teaching Reform Project of NWPU2018; Higher Education Research Fund of NWPU (G2018KY0207).

\section{References}

Austin, J. (1962). How to do things with words. Oxford: Clarendon.

Beer, F. A., \& De Landtsheer, C. (Eds.). (2004). Metaphorical world politics. East Lansing: Michigan State University Press.

Croft, W. (2009). Toward a social cognitive linguistics. In V. Evans \& S. Pourcel (Eds.), New directions in cognitive linguistics (pp. 395-42). Amsterdam \& Philadelphia: John Benjamins.

Croft, W., \& Cruse, A. (2004). Cognitive linguistics. Cambridge: Cambridge University Press.

Charteris-Black., J. (2005). Politicians and rhetoric: The persuasive power of metaphor. Basingstoke; New York: Palgrave MacMillan.

Charteris-Black., J. (2004). Corpus approaches to critical metaphor analysis. New York: Palgrave-MacMillan.

Chilton, P. (1996). Security metaphors: Cold war discourse from containment to common house. New York: Peter Lang.

Chilton, P. (2005a). Missing links in mainstream CDA: Modules, blends and the critical instinct. In R. Wodak \& P. Chilton (Eds.), A new agenda in (critical) discourse analysis (pp. 19-52). Amsterdam: John Benjamins.

Chilton, P. (2005b). Manipulation, memes and metaphors: The case of Mein Kampf. In L.D. Saussure \& P. Schulz (Eds.), Manipulation and ideologies in the twentieth century (pp. 15-44). Amsterdam: John Benjamins.

Dirven, R., \& Verspoor, M. (1998). Cognitive exploration of language and linguistics. Amsterdam: John Benjamins. Evans, V. (2006). Lexical concepts, cognitive models and meaning-construction. Cognitive Linguistics, 17(4). 491534.

Fairclough, N. (2001). Language and power. Harlow: Pearson Education.

Fauconnier, G. (1997). Mapping in thought and language. Cambridge: Cambridge University Press.

Fauconnier, G. \& Turner, M. (2002). The way we think:Conceptual blending and the mind's hidden complexities. New York: Basic Books.

Fowler, R. (1991). Language in the news: Discourse and ideology in the press. London: Routledge.

Geeraerts, D. (2016). The sociosemiotic commitment. Cognitive Linguistics, 27, (40), 26-41.

Gibbs, R. (1999). Intentions in the experience of meaning. New York: Cambridge University Press.

Grady, J., Oakley, T., \& Coulson, S. (1999). Blending and metaphor. In G. Steen \& R. Gibbs (Eds.), Metaphor in cognitive linguistics (pp.101-124). Philadelphia: John Benjamins

Hart, C. (2008). Critical discourse analysis and metaphor: toward a theoretical framework. Critical Discourse Studies, 5(2), 91-106.

Hart, C. (2011). Moving beyond metaphor in the cognitive linguistic approach to CDA. In C. Hart (Ed), Critical discourse studies in context and cognition (pp.172-193). Amsterdam: John Benjamins.

Harder, P. (2010). Meaning in mind and society: A functional contribution to the social turn in cognitive linguistics. Berlin \& New York: De Gruyter Mouton.

Hawkins, M. (19970. Social Darwinism in European and American thought, 1860-1945: Nature as model and nature as threat. Amsterdam: John Benjamins.

Halliday, M., \& Matthiessen, C. (1999). Constructing experience through meaning: A language-based approach to cognition. London: Continuum.

Halliday, M.A.K. (1985). An introduction to functional grammar. London:Arnold. 
Kristiansen, G., \& Dirven, R. (2008). Cognitive sociolinguistics: Language variation, cultural models, social systems. Berlin: Mouton de Gruyter.

Lakoff, G., \& Johnson, M. (1980). Metaphors we live by. Chicago: University of Chicago Press.

Lakoff, G. (1987). Women, fire and dangerous things. Chicago: University of Chicago Press.

Lakoff, G. (1996). Moral politics: What conservatives know that liberals don't. Chicago: University of Chicago Press.

Lakoff, G. \& Johnson, M. (1999). Philosophy in the flesh: The embodied mind and its challenge to western thought. New York :Basic Books.

Lakoff, G. (2006). Whose freedom?: The battle over America's most important idea. New York: Farrar, Straus and Giroux.

Lakoff, G. (2008). The political mind: Why you can't understand 21st-century politics with an 18th-century brain. New York:Viking Press.

Langacker, R. (1998). Conceptualization, symbolization and grammar. In M. Tomasello (Ed.), The new psychology of language: cognitive and functional approaches to language (pp. 1-39). Mahwah, NJ: Erlbaum.

Langacker, R.W. (1991) Foundations of cognitive grammar Vol. II: Descriptive application. California: Stanford University Press.

Langacker, R.W. (2008). Cognitive grammar: A basic introduction. Cambridge: Oxford University Press.

Paribakht, T. S., \& Wesche, M. (1997). Vocabulary enhancement activities and reading for meaning in second language vocabulary acquisition. Second language vocabulary acquisition: A rationale for pedagogy, 55(4), 174200.

Perrez, J., Reuchamp, M. (2015). The political impact of metaphors. Special Issue of Metaphor and the Social World, 5(2), 165-176.

Santa Ana, O. (2002). Brown tide rising: Metaphors of Latinos in contemporary American public discourse. Austin: University of Texas Press.

Steen, G. (1997). From Linguistic to Conceptual Metaphor in Five Steps. in R.W. Gibbs Jr and G.J. Steen (eds.), Metaphor in Cognitive Linguistics (pp. 57-77). Amsterdam: Benjamins.

Stubbs, M. (1997). Whorf's children: Critical comments on critical discourse analysis.

In A. Ryan and A. Wray (Eds), Evolving models of language (pp.101-135). Clevedon: British Association for Applied Linguistics.

Ungerer, F., \& Schmid, H. (2006). An introduction to cognitive linguistics. London: Longman.

Van Dijk, T.A. (1985). Cognitive situation models in discourse production: The expression of ethnic situations in prejudiced discourse. In J. P. Forgas (Ed), Language and Social Situations (pp.1-37). New York: Springer.

Van Dijk, T.A. (1995). Discourse analysis as ideology analysis. In C. Schaffner \& A.

Wenden (Eds), Language and peace (pp.1-35). Amsterdam: Harwood Academic Publisher.

Van Dijk, T. A.(1993). Elite discourse and racism. London: Sage Publications.

Van Dijk, T. A. (1998). Ideology: A multidisciplinary approach. London: Sage.

Van Dijk, T. A. (2002). Political discourse and political cognition. In P. Chilton and C. Schaffner (Eds), Politics as text and talk: Analytic approaches to political discourse (pp. 203-245). Amsterdam: John Benjamins.

Van Dijk, T. A. (2008). Discourse and contexts: A social-cognitive approach. Cambridge: Cambridge University Press.

Van Dijk, T.A. (2009). Society and discourse: How social contexts influence text and talk. Cambridge: Cambridge University Press.

Walter, J., \& Helmig, J. (2008). Discursive metaphor analysis: (De)construction(s) of Europe. In T. Carver \& J.Pikalo (Eds), Political language and metaphor: interpreting and changing the world (pp.119-131). New York: Routledge.

Wodak, R. (2001). What is CDA about: A summary of its history, important, important concepts and its developments. In R. Wodak \& M. Meyer (Eds), Methods of critical discourse analysis (pp.1-31). London: Sage.

Wodak, R. (2006). Mediation between discourse and society: Assessing cognitive approaches in CDA. Discourse Studies, 8 (1), 179-190. 